\title{
Life-cycle of Paracoenogonimus ussuriensis sp. n. (Digenea: Cyathocotylidae) in the Primorsky region (southern Far East, Russia)
}

\author{
V. V. BESPROZVANNYKH, A. V. ERMOLENKO \\ Institute of Biology and Soil Sciences, Far East Branch of the Russian Academy of Sciences, \\ prospect 100-letija, 159, Vladivostok 690022, Russia, E-mail: besproz@ibss.dvo.ru
}

\begin{abstract}
Summary
New cercariae similar to those of Paracoenogonimus (Cyathocotylidae, Prohemistomatinae), have been found in gastropods Amuropaludina and Cipangopaludina from reservoirs of the Primorsky Region (southern Far East of Russia). Two species of freshwater fishes (Pseudorasbora parva and Perccottus glenii) were experimentally-infected second intermediate hosts. Adults reared in chicken, Gallus gallus dom. They belong to a new species, Paracoenogonimus ussuriensis sp. n. They differ from those of $P$. szidati (Anderson, 1914) and Mesostephanus appendiculatus (Ciurea, 1916) (=P. skworzowi (Petrov, 1950) sensu Sudarikov 1961) by the size of the body, pharynx and ovary and, further, from the latter by the size of the suckers and testes. Adults differ from P. ovatus Katsurada, 1914 by the smaller dimensions of the oral sucker, pharynx and testes, and also by the absence of anterior interval between vitelline follicles.

Key words: Paracoenogonimus ussuriensis sp. n., lifecycle, sporocyst, cercaria, metacercaria, adult worm, taxonomy.

\section{Introduction}

A new furcocercaria, morphologically similar to those of the cyathocotylid subfamily Prohemistomatinae, has been found in freshwater snails of the genera Amuropaludina and Cipangopaludina collected in the Primorsky Region (southern Far East of Russia). During subsequent experimental investigations, we were able to grow metacercariae and adult worms, and to establish that they belonged to a new species of the genus Paracoenogonimus, - P. ussuriensis sp. n. The cercaria, metacercaria and adult are described and illustrated here.
\end{abstract}

\section{Material and methods}

Gastropod species Amuropaludina praerosa (Gerstfeldt)
(Amuropaludinidae) and Cipangopaludina ussuriensis (Gerstfeldt) (Bellamyidae) (1000 specimens each) were collected from the lower part of the Arsenjevka River (Amuropaludina) and a lake belonging to its basin (Cipangopaludina), respectively. Parthenitae and cercariae of $P$. ussuriensis $\mathrm{sp}$. $\mathrm{n}$. were found only in two specimens. The biology of the digeneans was studied in laboratory conditions at water temperature $18-22^{\circ} \mathrm{C}$.

The life-span of cercariae was established experimentally. Infected snails were placed in Petri dishes filled with water for 20 - 30 minutes. Cercariae emerging from snails during this period were assumed to be the same age. The maximal life-spanwas defined from the moment of emergence until they all died.

Narrow extended glass dishes $(20 \times 2 \times 3 \mathrm{~cm})$ on $1 / 3$ closed black paper and bright dot illumination at the opposite side of a vessel were used study cercarial reaction to light. Behavior of cercariae was observed on a group of specimens emerging from snails at a peak of emission, in Petri dishes with high boards. To study the daily rhythm of emergence, snails were placed in Petri dishes with $50 \mathrm{ml}$ of water. Dishes with cercariae were shaken up every two hours and ten samples $(1 \mathrm{ml}$ each), were taken by means of a graduated pipette. Cercariae in each sample were fixed by iodine solution, and then counted.

The number of cercariae in samples increased fifty times on average. Measurements of parthenitae and metacercariae were made on live specimens. Cercariae were killed in hot $4 \%$ formalin. Chaetotaxy was studied in stained living specimens using $1 \%$ solution of silver nitrate as described by Ginetsinskaja and Dobrovolsky (1963). The position of sensillae was described according to Richard (1971).

To investigate the second intermediate host, we exposed uninfected fish from natural reservoirs, to snails emitting cercariae. Juvenile fishes Pseudorasbora parva (Schlegel) (Cyprinidae) and Perccottus glenii Dybowski (Odontobu- 


tidae) (5 specimens each), tadpoles Rana dybowskii Günther juv. (Ranidae) (10 specimens) and snails Anisus centrifugops Prosorova et Starobogatov (Planorbidae), Boreoelona ussuriensis (Ehrmann) (Bithyniidae), Cipangopaludina ussuriensis (Bellamyidae) (5 specimens each) were used in the experiment. In addition, 50 specimens of each group of animals were examined as controls.

Adults were reared in a laboratory-bred chicken. They were washed in distilled water, killed in boiling distilled water, and preserved in $70 \%$ ethanol. Whole-mounts were stained with alum carmine, dehydrated in a graded ethanol series and cleared in xylene, then mounting in Canada balsam. Measurements are given in millimeters $(\mathrm{mm})$ in Table 1 .

\section{Results}

Paracoenogonimus ussuriensis sp. $\mathrm{n}$.

Definitive host (experimentally): chicken Gallus gallus dom.
Site: Anterior part of small intestine.

Type habitat: Lower part of Arsenjevka River (a tributary of Ussuri River) Primorsky Region, southern Far East of

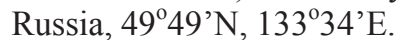

Material examined: Sporocysts: 5 specimens; Cercariae: 25; Metacercariae: 15; Adults: 10.

Type-deposition: Holotype No 34-Tr, paratype No 35-Tr. This material is held in the parasitological collection of the Zoological Museum (Institute of Biology and Soil Sciences, Far East Branch of the Russian Academy of Sciences, Vladivostok, Russia); e-mail: petrova@ibss.dvo.ru. Deposited: 2007.22.07.

Etymology: The specific name refers to the Ussuri River basin, the type-locality

First intermediate hosts: Gastropoda - Amuropaludina praerosa (Amuropaludinidae) and Cipangopaludina ussuriensis (Bellamyidae)

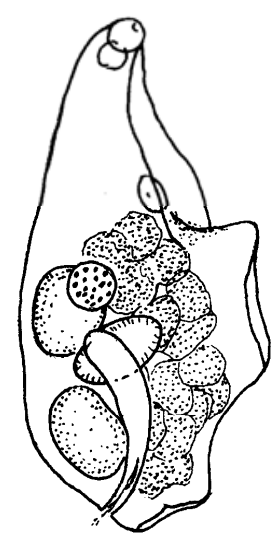

b

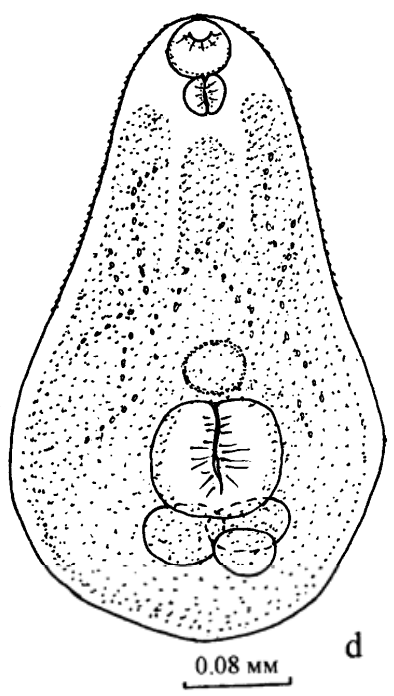


Sporocyst (Fig. 1a). Threadlike mobile specimens, $6.65-$ $7.66 \times 0.21-0.23$, with terminal genital pore. In the liver of snails they intertwine, forming a ball.

Cercaria (Fig. 1b). Body (sizes given in Table 1) oval, ventrally concave. Surface is covered with spines, more numerous at level of terminal organ. Pharynx nearly at terminal organ. Oesophagus short. Caeca long, terminating blindly near middle excretory vesicle. Ventral sucker absent. Gland-cells in two groups of 4 cells each, at level of terminal organ; ducts open at anterior end of body. In addition, numerous cells located laterally from anterior end of body to its posterior quarter, opening on ventral surface.

Excretory system includes a vesicle, and several channels. Two lateral collecting channels joined by transverse duct at level of intestinal bifurcation. Median duct connected to transverse duct and divided into two branches, which open into excretory vesicle. Transverse duct with two small blind offshoots, located on both sides of median channel. Caudal channel penetrates tail stem and furcae and opens at their ends. Flame cell formula: $2[(3+3+3)+$ $(3+3+[3])]=36$. Tail stem with 7 pairs of caudal cells. Furcae with bent lateral edges, flat dorso-ventrally. Sensory apparatus (Fig. 2): $\mathrm{CI}=6 \mathrm{~V}_{1}, 2 \mathrm{~V}_{2}, 2 \mathrm{~V}_{3}, 3 \mathrm{D}$; $\mathrm{CII}=2 \mathrm{~V}_{1}, 2 \mathrm{~V}_{2}$, $3 \mathrm{D}, 4 \mathrm{~L} ; \mathrm{CIII}=4 \mathrm{D}, 4 \mathrm{~L} ; \mathrm{CIV}=1 \mathrm{~V}_{1}, 1 \mathrm{~V}_{2}, 3 \mathrm{D}, 3 \mathrm{~L} ; \mathrm{CV}=3 \mathrm{D}$; $\mathrm{AI}=3 \mathrm{~V} ; 3 \mathrm{D}, 13 \mathrm{~L} ; \mathrm{AII}=1 \mathrm{~V}_{0}, 7 \mathrm{~V}_{1}, 5 \mathrm{D}, 12 \mathrm{~L} ; \mathrm{AIII}=2 \mathrm{~V}$, $9 \mathrm{~L} ; \mathrm{M}=2 \mathrm{~V}, 2 \mathrm{D}, 6 \mathrm{~L} ; \mathrm{P}=2 \mathrm{~V}, 1 \mathrm{D}, 1 \mathrm{~L}$. Tail stem and furcae covered with numerous sensillae. Eight longitudinal rows present on tail stem: two lateral ones on each side, three rows dorsally and ventrally; each median row consists of 3 -4 sensillae.

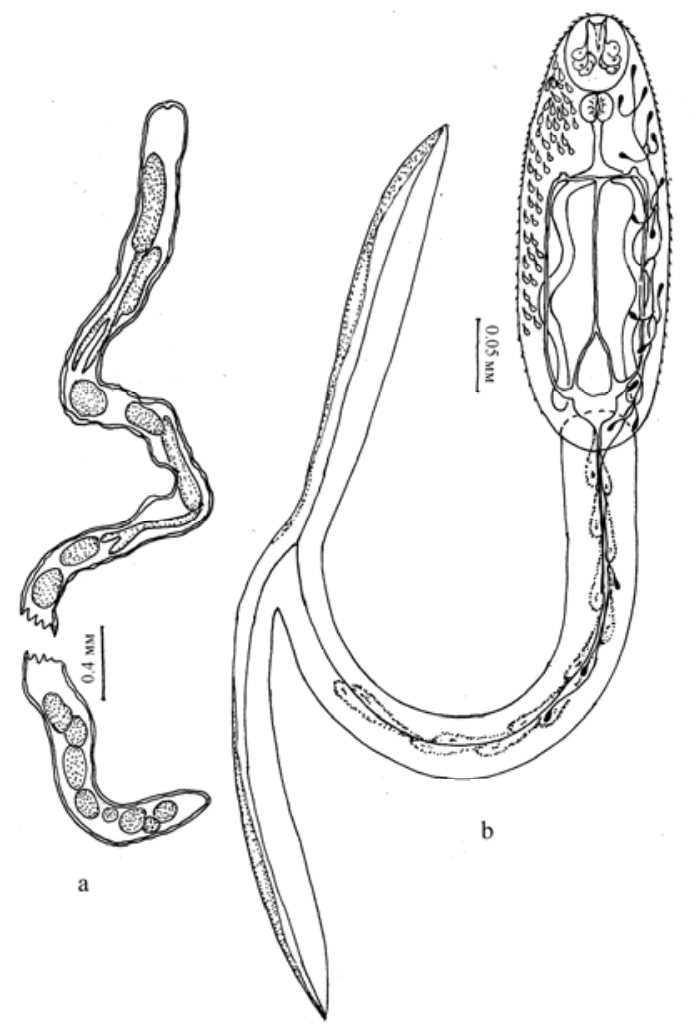

Fig. 2. Paracoenogonimus ussuriensis sp. n. $\mathrm{a}$ - sporocvst: $\mathrm{b}$ - cercaria
Second intermediate hosts: fishes - Pseudorasbora parva (Cyprinidae), Perccottus glenii (Odontobutidae) (experimentally).

Metacercaria (Fig. 3c, d). Body enclosed in round thickwalled cyst (see Table 1). Cyst-wall transparent, 0.056$0.084 \mathrm{~mm}$. Body extracted from cyst, pear-shaped. Anterior half covered with very small spines. Oral sucker contiguous with pharynx. Oesophagus short. Caeca are mostly concealed by excretory system. Ventral sucker underdeveloped, indistinct (approximately $0.033-0.044 \mathrm{~mm}$ ), anterior to Brande's organ. Primodia of two testes $(0.033-$ $0.041-0.052-0.055 \mathrm{~mm})$ and ovary $(0.033 \times 0.055 \mathrm{~mm})$ posterior to Brande's organ. Channels of secondary excretory systems filled with granules, and form three branches in shape of W.

\section{Definitive host: Gallus gallus dom. (experimentally).}

Adult worm (holotype). Body 0.74 x $0.40 \mathrm{~mm}$, pear-shaped (Fig. 3a), with a small caudal appendage (size varied among 10 digeneans examined). Body lacks spines. Shallow ventral concavity anterior to Brande's organ. Oral sucker 0.044 x $0.049 \mathrm{~mm}$. Prepharynx absent, pharynx $0.033 \times 0.035 \mathrm{~mm}$. Oesophagus short, $0.069 \mathrm{~mm}$. Caeca reach middle of posterior testis. Ventral sucker $0.052 \mathrm{x}$ $0.055 \mathrm{~mm}$, underdeveloped, with indistinct edges, just anterior to Brande's organ. Brande's organ slightly prominent over ventral surface of body $0.34 \mathrm{~mm}$ from anterior end, its diameter $0.20 \mathrm{~mm}$ (Fig. 3b). Testes median, posterior at level of Brande's organ. Distance between testes $0.056 \mathrm{~mm}$. Anterior testis $0.11 \times 0.12 \mathrm{~mm}$, posterior $0.11 \mathrm{x}$ $0.14 \mathrm{~mm}$. Ovary 0.069 × $0.063 \mathrm{~mm}$, almost median, at level of anterior testis, adjoining it ventrally. Cirrus-sac $0.24 \times 0.035 \mathrm{~mm}$, with tubular seminal vesicle. Bottom of sac reaches anterior testis and opens on dorsal surface between body and caudal appendage. Large vitelline follicles $(20-24)$ form semicircle (10 to12 on each side) around gonads, partly covering testes. Left and right vitelline fields interrupted at level of posterior testis. Eggs large (usually $1-2$ eggs in uterus).

\section{Discussion}

The absence of a vaginal sphincter, the presence of a ventral concavity, a tubular seminal vesicle, a small caudal appendage, and the position of the testes in tandem on a longitudinal axis indicate that the species belongs to the genus Paracoenogonimus.

This genus is recorded for the first time in the Russian Far East. All worms belonging to this and related genera, have been previously found in Europe and North America (Ginetsinskaja \& Koscheva, 1959; Katsurada, 1914; Komiya, 1938; Schulman et al., 2005; Sobecka et al., 2004; Sudarikov, 1961).

The new species and other species of the genus, Paracoenogonimus ovatus Katsurada, 1914 and P. szidati (Anderson, 1944), such as Mesostephanus appendiculatus 

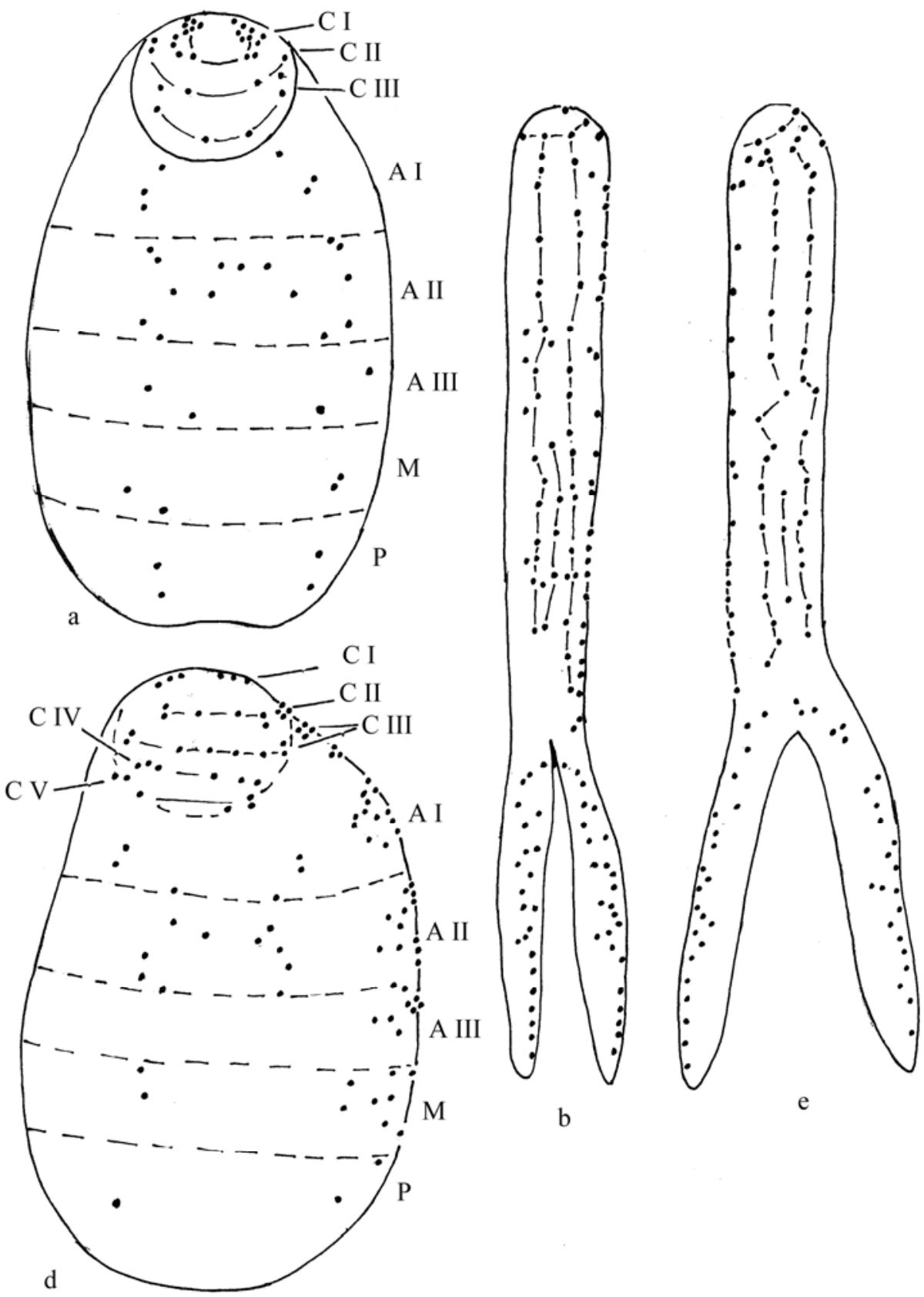

Fig. 3. Distribution of sensillae on cercarial body and tail of Paracoenogonimus ussuriensis sp. n. a, b-ventral; d, e - dorsal

(Ciurea, 1916) (formerly P. skworzowi (Petrov, 1950) sensu Sudarikov 1961) use fish as second intermediate hosts in their life-cycle, whereas Linstowiella viviparae (Linstow, 1877) (formerly P. viviparae sensu Sudarikov 1916) uses molluscs (Michenko, 1974; Niewiadomska, 2002).

P. ussuriensis sp. n. differs from $P$. szidati by the dimensions of the body, pharynx and ovary; and from Mesostephanus appendiculatus, described by Petrov (1950) as M. skworzowi, in addition, by the absence of a vaginal sphincter, the dimensions of the suckers and testes (see Table 2). Moreover, in P. szidati the left and right vitelline fields are interrupted posteriorly, while in $P$. ussuriensis sp. $\mathrm{n}$. the interruption is anterior. The number of follicles varies from 30 to 35 in Mesostephanus appendiculatus (according to Petrov) and 20-24 in the new species.

The new species most closely resembles of $P$. ovatus; however, it differs from specimens described by Katsurada (1914) and redescribed by Komiya (1938) by the smaller dimensions of the oral sucker and pharynx, and also by the larger ventral sucker (Table 2). Also, the testes in $P$. ovatus are located in the posterior third of the body diagonally to the median line, bordering upon each other. The vitella- 
rium in $P$. ovatus forms two groups of follicles interrupted at the levels of anterior and the posterior testis, whereas the vitellarium of $P$. ussuriensis $\mathrm{sp}$. $\mathrm{n}$. forms a semicircle interrupted only at the level of the posterior testis.

The new species differs from specimens of P. ovatus, studied by Golovin (1958; cit by: Sudarikov, 1961), by the interruption between the vitelline fields, and the dimensions of suckers, pharynx and Brandes'organ only (Table 2).

Minimal differences were found between our worms and specimens of " $P$. ovatus", studied by Ginetsinskaja and Koscheva (1959). These authors obtained adult worms and identified them as P. ovatus. The new species differs from those only by the dimensions of the pharynx. However, Ginetsinskaja \& Koscheva infected the definitive host with metacercaria from naturally infected fishes of the Volga River basin. In this case, it is most likely that they obtained not $P$. ovatus, but another cyathocotylid digenean (for example, Holostephanus or Cyathocotyle) common in Europe. Some cyathocotylids (such as C. oviformis Szidat, 1936, H. cobitidis Opravilova, 1968 and others) resemble $P$. ovatus by the dimensions of the body and various organs. Furthermore, the description given by Ginetsinskaja \& Koscheva, was not complete and did not include any figures, so we could not adequately compare $P$. ussuriensis sp. n. with their worms.

Cercariae and metacercariae of $P$. ussuriensis sp. n. differ from those of $P$. ovatus by the dimensions of body; this supports the validity of the new species. Thus, the cercarial body of $P$. ussuriensis sp. $\mathrm{n}$. and its terminal organ and pharynx are smaller than those of $P$. ovatus published by Komiya (1938). Besides, cercaria of the new species has collecting channels of the excretory system with two unforked blind appendices and four pairs of glands with ducts openin the anterior part of the body. Collecting channels of the excretory system in cercaria of $P$. ovatus have two Yshaped appendices (according to Komiya, 1938) or lack of them (according to Ginetsinskaja \& Koscheva, 1959). Cercaria of $P$. ovatus have 5-7 (Ginetsinskaja \& Koscheva) or 7 (Komiya) pairs of glands with ducts openingin the anterior part of the body.

The metacercaria of $P$. ovatus has a bigger cyst (according to Komiya), or larger body, oral sucker, pharynx and Brandes'organ (according to Ginetsinskaja \& Koscheva) in comparison with metacercaria of $P$. ussuriensis sp. $\mathrm{n}$.

The first intermediate host of $P$. ovatus is a gastropod of the genus Viviparus (Viviparidae, Vivipariformes) (Komiya 1938). The first intermediate hosts of P. ussuriensis sp. n. are molluses from the genera Amurodaludina (Amuropaludunidae) and Cipangopaludina (Bellamyidae) belonging to the same order.

We believe that these differences sufficient to establish a new species.

Life-cycle. Cercariae emerge from the snails in daylight from 10 am to $5 \mathrm{pm}$ with peak emission (up to 2.5 thousand specimens) from 11 am to $3 \mathrm{pm}$. Actively floating cercariae were positive rheotactic and feebly expressed phototaxis (up to $60 \%$ preferred the most spotlit side of a dish). Periods of active floating cercariae alternated with dormant periods, but the presence of any irritant (fish, larval insect or an object, causing water disturbance near the cercariae) stimulates extraordinary activity. It has been experimentally established that fishes are the second intermediate hosts. All exposed specimens of Pseudorasbora parva and Perccottus glenii became infected, with 20 - 45 metacercariae per fish. Attempts to infect tadpoles and snails failed. We observed that when floating cercariae encountered a fish, they fixed on the body (they are able to creep all over a fish searching for the most accessible spot for penetration), and actively penetrated the internal tissues, where they localized in the muscles. Sixty metacercariae were given to a chicken on the $40^{\text {th }}$ day after fish had been infected, and 7 days later, 35 adult trematodes of P. ussuriensis sp. $\mathrm{n}$. were found in the small intestine.

\section{Acknowledgments}

Partial funding support for this research by grants 04-1OBN-061 and 06-1-OBN-088 is gratefully acknowledged.

\section{References}

Ginetsinskaja, T. A., Dobrovolsky, A. A. (1963): [A new method of finding sensilla on trematodes larvae and its value for systematic]. Reports. AS of USSR, 151, 2: 460 - 463 (In Russian)

Ginetsinskaja, T. A., Koscheva, A. F. (1959): [About the lifecycle and systematic status of Paracoenogonimus ovatus Katsurada (Trematoda) and identity of metacercariae of this species with Neodiplostomum hughes Markewitsh]. Vestnik Leningradskogo universiteta, Vol. 2, No 9: 68 - 75 (In Russian)

KatsuradA, F. (1914): Studien uber Trematoden bei SuBwasserfischen, mit besonderer Beruksichtigung der Elb- und Alsterfische Zbl. Bakteriol., Orig., Bd. 73, No 4 $-5: 304-314$

KomiYA, Y. (1938): Die Entwicklung des Exkretionssystems einiger Trematodenlarven aus Alster und Elbe, nebst Bemerkungen uber ihren Entwicklungszyklus. Z. Parasitenkunde, Bd. 10, No 3: 625 - 654

MiCHENKO, V. F. (1974) [Lifecycle and ontogenesis of trematode Linstowiella viviparae (Prohemistomatidae)]. Ecologia i geografia hel'mintov. Trudy hel'mintologitscheskoy laboratorii. Vol. 24: 102 - 112 (In Russian)

NiEWIAdOMSKA, K. (2002): Family Cyathocotylidae Mühling, 1898. In: GIBSON D. I., JONES A., BRAY R. A. (Eds) Keys to the Trematoda. CABI Publishing, Wallingford and The Natural History Museum. Vol. 1: $201-215$ Petrov, A. M. (1950): [New trematoda from intesine of cat - Mesostephanus skworzowi nov.sp. (Strigeata)]. Trudy Vsesojuznogo Instituta hel'mintologii imeni akademica $K$. I. Skrjabina. Vol. 4: 81 - 82 (In Russian)

RICHARD, J. (1971): La chetotaxie des cercaries valeur systematique et phyletique. Memoires du Museum National d'Histoire Naturelle, 67: 79

Schulman, B. S., Ieschko, E. P., Tschurov, B. O., Yensen B. O., Yensen A. (2005): [A peculiarities of 
parasite fauna in fishes from river Vefsna (North Norway)]. Lososevidnyje ryby Vostotschnoy Fennoscandii. Petrozavodsk: 191 - 194 (In Russian)

SobeckA, E., Jurkiewicz, E., Piasecki, W. (2004):

Parasite fauna of ide, Leuciscus idus (L.) in lake Dnbie

RECEIVED SEPTEMBER 2, 2008
Poland. Acta Ichtyol. Piscatoria, Vol. 34, No 1: 33 - 42 SudARIKOV, V. E. (1961): [Order Strigeidida (La Rue, 1926) Sudarikov, 1959] / Skrjabin K.I. Trematody zhivotnykh $i$ tscheloveka. Osnovy trematodologii. M.: Academy of Science of USSR, 19: 269 - 469 (In Russian) 